\title{
st \\ A primeira teoria evolucionista de Wallace
}

\author{
Marcio Rodrigues Horta
}

O naturalista inglês Alfred Russel Wallace nasceu em 8/1/1823 em Usk, Monmouthshire. Até morrer em Broadstone, em ₹/11/1913, escreveu prolificamente sobre biologia, socialismo e vários outros assuntos. Ele foi o oitavo dos nove filhos de Thomas Wallace e Mary Greenell, um casal de posses modestas que, não obstante, durante a sua infância, editou uma revista literária e manteve uma das livrarias da cidade, atividades que se mostraram favoráveis à formação do menino. Entrementes, esse período foi marcado pelas limitações que as dificuldades financeiras de sua família trouxeram e pela morte, pois quatro das cinco irmãs mais velhas do infante Alfred faleceram antes de alcançar a idade adulta. Como sua saúde também não era exemplar, em torno dele houve uma perene atmosfera de medo; mas o pior não adveio e, embora a considerasse tediosa, recebeu as primeiras letras na escola de gramática de Hertford. Sua tendência para o estudo e a presença de livros tanto na escola quanto em casa acabaram por fazer da leitura a atividade preferida do futuro cientista (cf. Smith, 2003a, p. 1; Tort, 1996, p. $45^{6} 5_{5}$ ).

Por volta de 1835 , a família do adolescente Alfred Wallace entrou numa crise econômica aguda e, no fim de 1836, aos treze anos, ele teve de deixar a escola e seguir rumo a Londres para trabalhar com o irmão John Wallace. No início de 1837, o jovem trabalhador conheceu alguns simpatizantes de Robert Owen, chegando a ouvir o próprio líder trabalhista discursar; desde então, tornou-se socialista, não-conformista e descrente das formas religiosas predominantes na Inglaterra. Em meados de 1837, partiu para Bedforshire, para aprender topografia com seu irmão William Wallace, que adquirira uma empresa do ramo; nos anos subseqüentes, dentre outras ciências, procurou aprender geometria, cartografia, botânica, geologia e astronomia. Por volta de 1841, associou-se aos institutos de mecânica de Hereford e de Neath, passando a fazer conferências sobre tecnologia e história natural (cf. Smith, 2003a, p. 2; Smith, 2003b, p. 1).

Em 1842, Wallace teve contato com o tema que haveria de empolgá-lo pelo resto de sua vida, ao ler o Tratado sobre a geografia e a classificação dos animais, de William Swainson. Esta obra, publicada em 1835, didaticamente expunha as diversas doutrinas sobre os centros de criação, da crença bíblica de que Deus criou as espécies tal como 
agora existem no jardim do Éden até os múltiplos centros de criação do criacionismo modificado do século dezenove; contudo, para esse teólogo natural, os mecanismos da dispersão posterior à criação, qualquer que fosse o seu modo correto, estariam fora das possibilidades do conhecimento humano, permanecendo assim um invencível mistério divino (cf. Tort, 1996, p. 4566). Alguns anos se passariam, até que a importância dessa primeira introdução a zoogeografia e sistemática se mostrasse por completo.

Nesse ínterim, no fim de 184,3, a firma de William entrou em crise e, no início de 1844, Wallace empregou-se no Collegiate School de Leicester como mestre-escola de desenho, topografia, inglês e aritmética; a boa biblioteca do colégio forneceu ao novo professor do primário acesso a várias obras importantes de história natural. No final desse ano e nessa cidade, conheceu o jovem naturalista Henry Bates que, apesar de moço, era um entomologista com alguma experiência - a coleção de insetos e as atividades de coleta do novo amigo logo capturaram o interesse de Wallace (cf. Smith, 2003a, p. 2).

Trabalhar e viver em Leicester, ainda que por pouco tempo, foi para Wallace de grande valia, pois nesse período pôde ler os relatos de viagem de Humboldt e Darwin; ademais, no plano teórico, a leitura dos Princípios de geologia mostrou-se decisiva para ele (cf. Tort, 1996, p. 4566) por duas razões: a) nessa obra, Charles Lyell desenvolveu uma teoria uniformitarista em geologia, sustentando que a superfície da Terra teria sempre se alterado fundamentalmente de forma gradual, tendo por agentes as forças naturais conhecidas, tais como a chuva, a neve, a erosão, a deposição, a sedimentação, o vento etc. Essa tese contrastava com a da escola criacionista ortodoxa, então dominante, para a qual a face do mundo seria o resultado de catástrofes periódicas, revoluções geológicas similares ao dilúvio bíblico; b) em biologia, para refutar o transformismo de Lamarck, Lyell expôs criteriosamente a filosofia zoológica do escritor francês; em seu lugar, o problema da extinção das espécies foi respondido com a tese do retorno das variedades à forma original para recompor a população extinta. Wallace adotou sem restrições o gradualismo naturalista, transpondo-o para o seu pensamento biológico; não obstante, com o tempo, a resposta de Lyell para o repovoamento da Terra veio a lhe parecer sumamente insatisfatória (cf. Horta, 2003, p. 241, n. 2).

Na páscoa de 1845 , William Wallace morreu inesperadamente, e Wallace retornou para Neath, no sul do País de Gales, para conduzir o negócio deixado pelo irmão (cf. Ferreira, 1990, p. 19); logo em seguida, irritado com os encargos das tarefas puramente administrativas, voltou a atuar como intelectual, tornando-se curador do Museu do Instituto de Filosofia e Literatura de Neath (cf. Smith, 2003a, p. 2). Sua formação teórica continuava em curso e, na carta para Bates de $9 / 11 / 1845$, Wallace escreveu sobre outra influência marcante que recebeu: no outono desse ano, leu um livro publicado anonimamente em 1844. (apenas na última edição, a de 1884, é que Robert Chambers se apresentou como o autor), os Vestígios da criação (cf. Ferreira, 1990, p. 19; Tort, 1996, 
p. $45^{6} 7$ ). Sua posição central, que marcou profundamente o pensamento de Wallace, é a que segue:

a idéia que concebo do progresso da vida orgânica sobre o globo ... é que o tipo mais simples e mais primitivo (sob uma lei à qual está subordinada a produção do semelhante) deu origem ao tipo seguinte acima dele e este produziu o próximo tipo mais elevado - assim sucessivamente, até o mais alto de todos; como os graus de avanço, em todos os casos, sempre foram pequenos (a saber, apenas de uma espécie a outra), o fenômeno sempre possuiu um caráter simples e modesto (apud Papavero \& Bousquets, 1994, p. 20).

Possivelmente por não ter sido educado na biologia e teologia ortodoxas, Wallace mostrou-se aberto à tese advogada por Chambers, sobre a continuidade natural e progressiva na história dos seres vivos. Entusiasmado, na carta para Bates de 28/12/45, Wallace escreveu que os Vestígios da criação sustentavam uma "hipótese engenhosa fortemente apoiada sobre fatos e analogias impressionantes, mas que resta provar" e que o papel do naturalista era descobrir o que "cada fato que se observa pode indicar seja a favor ou contra esta hipótese” (apud Tort, 1996, p. 4567). Nessa época, Wallace entendeu que o futuro imediato da ciência biológica de ponta consistia em evidenciar a evolução contínua, gradual e progressiva dos seres vivos, além de demonstrar como o seu mecanismo ou causa eficiente opera, originando as espécies de forma estritamente natural (cf. Horta, 2003, p. 219; Horta, 1998).

A inquietude existencial de Wallace, manifesta em sua insatisfação profissional, sugere que sua vocação para a história natural o pressionava e, em 1847, quando da oportuna leitura de Uma viagem Amazonas acima, do americano Witt Edwards, uma forma alternativa de ganhar a vida se lhe apresentou: ele resolveu tornar-se um profissional em história natural (cf. Ferreira, 1990, p. 23). Em 184,8, Wallace convenceu Bates a acompanhá-lo à bacia amazônica com um triplo intento: 1) remeter espécies zoológicas para museus e amadores ricos; 2) estudar a relação entre as espécies mais ou menos isoladas e os afluentes do Amazonas; 3 ) verificar se a transmutação resulta da modificação de uma espécie preexistente, por meio do processo natural de geração (cf. Tort, 1996, p. 4567). Nas palavras de Bates:

o plano consistia em fazermos uma coleção de objetos, i.e., insetos, pássaros, peixes etc., vender as duplicatas em Londres para pagar as despesas, e assim obter dados com o objetivo, como o Sr. Wallace se expressou em uma das suas cartas, de resolver o problema da origem das espécies, um assunto sobre o qual tínhamos conversado muito e discutido na nossa correspondência (apud Ferreira, 1990, p. 22). 


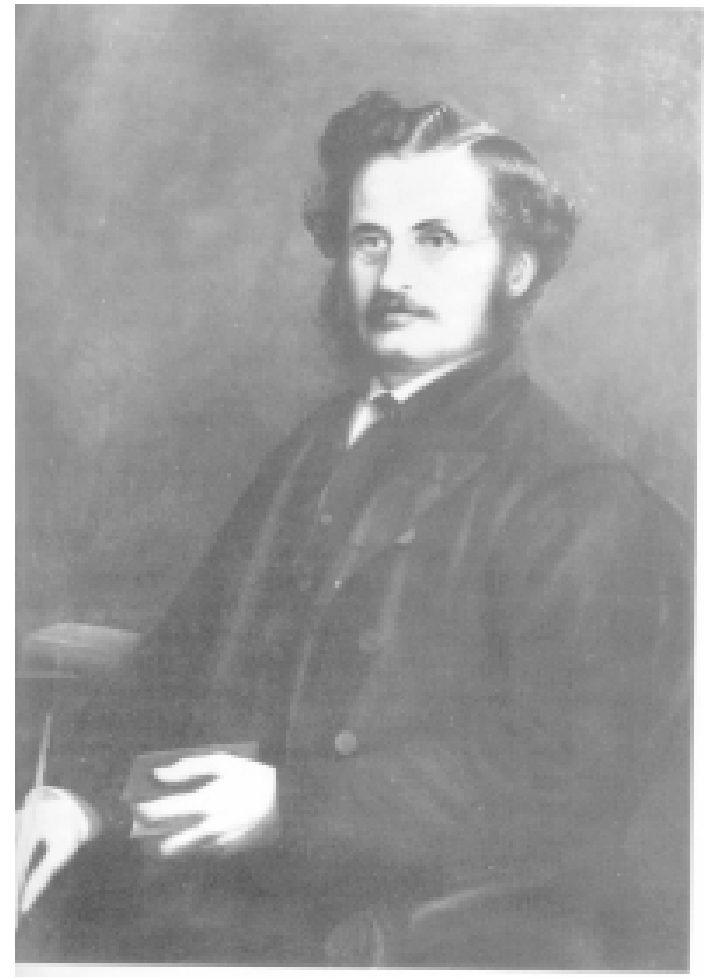

Figura 1. Henry Bates ensinou os fundamentos de entomologia a Wallace e o acompanhou em sua viagem ao Amazonas.
Em 24/04/1848, Wallace (com vinte e cinco anos) e Bates (com vinte e três) partiram para Belém rumo ao rio Amazonas e, em 28/05/184, desembarcaram no Pará; no plano teórico, ambos estavam interessados, principalmente, na distribuição das borboletas e aves em função da presença ou da ausência de barreiras naturais, a chave que então dispunham para o problema da origem das espécies. Essa hipótese talvez seja devida à leitura de Buffon, para quem possivelmente:

todos esses animais do novo mundo seriam, no fundo, os mesmos do antigo, dos quais outrora obtiveram sua origem: poder-se-ia dizer que, sendo em algum momento separados por mares imensos ou por terras impraticáveis, com o tempo eles receberam todas as impressões e sofreram todos os efeitos de um clima rigoroso (novo,

mesmo), e que também mudaram de qualidade pelas mesmas causas que produziram a separação; que, em consequiência, eles diminuíram com o tempo, se desnaturalizaram etc. (apud Papavero \& Bousquets, 1994, p. 6).

Wallace e Bates trabalharam juntos até fins de 1848, quando fizeram uma expedição pelo Tocantins; então, Wallace seguiu para o Rio Negro e Bates para o Solimões (em 1850, reencontraram-se brevemente). Bates permaneceu na região por onze anos, só retornando à Inglaterra em 1859 (cf. Ferreira, 1990, p. 25); em 1861, publicou um artigo sobre o mimetismo nas borboletas amazônicas que Darwin recebeu com entusiasmo, pois nele há praticamente a observação da formação natural de uma nova espécie de borboleta, através da união de um tipo de semelhança mimética (cf. Tort, 1996, p. 4567), a partir de então chamada "batesiana", com a seleção natural. Por sua vez, Wallace subiu o Rio Negro para além do que qualquer outro europeu jamais houvera ido, desenhando um mapa da região suficientemente acurado para tornar-se padrão por muitos anos. Imbuído do uniformitarismo de Lyell e do evolucionismo de Chambers, ele buscava fatos que fornecessem não apenas uma gradual descendência 
natural, mas um princípio de divergência que permitisse apresentar a sistemática como uma árvore ramificada, como postulara Hugh Strickland (cf. Tort, 1996, p. 4153), para quem:

O sistema natural pode ser, talvez, melhor comparado com uma árvore irregularmente ramificada, ou com um conjunto de árvores e arbustos separados, de vários tamanhos e modos de crescimento (apud Papavero \& Bousquets, 1994, p. 22-3).

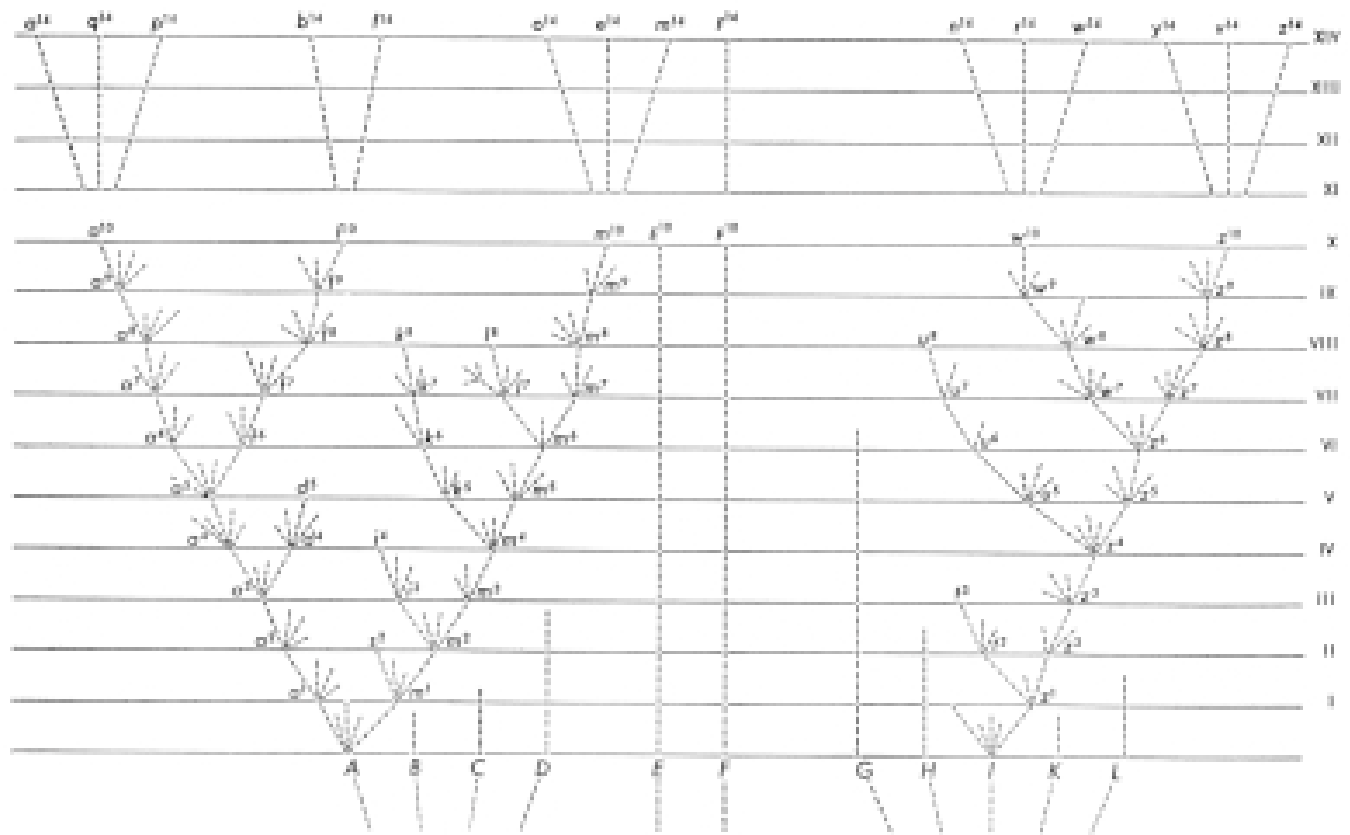

Figura 2. A estrutura do sistema natural darwiniano, apresentada em $A$ origem das espécies, ilustra a proposta de Strickland defendida por Wallace.

Apesar de ser a sua melhor hipótese, a ramificação por separação geográfica da população das espécies devida a eventos geológicos daria tanto? No início de 1852, quatro anos após chegar à Amazônia, Wallace estava doente e sem condições de continuar; decidiu então retornar à Inglaterra, começando uma longa viagem de volta pelo Rio Negro e Amazonas até Belém. Quando finalmente alcançou essa cidade, em 2///1852, soube que seu irmão mais jovem, Herbert (que esteve trabalhando na região desde 1849), morrera de febre amarela tentando embarcar do Pará para a Inglaterra, em $185^{1}$ (cf. Smith, 2003a, p. 3). Abalado emocionalmente e teoricamente insatisfeito, Wallace juntou suas coleções pessoais, os volumes de seu diário e partiu; surpreendentemente, 
em 6/8/1852, o barco em que velejava pegou fogo e afundou, levando tudo (com exceção de parte do diário e alguns desenhos de peixes do Rio Negro) - por dez dias Wallace e outros náufragos sobreviveram em botes precários, sendo salvos por um cargueiro que passava rumo à Inglaterra, onde chegou em 1/10/1852 (cf. Smith, 2003a, p. 3; Ferreira, 1990, p. 33).

Em 1853, Wallace publicou Uma narrativa de viagens no Amazonas e no Rio Negro, no qual sustentou que a dispersão das espécies e das variedades nas margens desse braço do Amazonas se relaciona a sua condição de obstáculo geográfico. Embora positiva, o livro teve uma repercussão muito pequena, e a velha dificuldade financeira voltou a se apresentar: com vinte e nove anos, Wallace era razoavelmente conhecido como naturalista viajante, mas precisava voltar ao trabalho. Provavelmente, a escolha de viajar para o Arquipélago Malaio ligava-se à sua convicção de que a hipótese da separação geográfica da população das espécies devida a eventos geológicos podia explicar satisfatoriamente a origem das espécies; assim, ele procurou um lugar em que a descontinuidade espacial é a regra.

Em meados do século XIX, a região do Arquipélago Malaio era pouco explorada e perigosa - entre 1821 e 1851, ao menos doze zoólogos ali morreram. Todavia, como evolucionista, Wallace deve tê-la avaliado como cientificamente estratégica, em razão da presença de tribos "não-civilizadas" e orangotangos (cf. Tort, 1996, p. 4567). Apesar de considerá-las uma chave para a evolução, ao retornar da Amazônia para a Inglaterra, Wallace manifestava uma posição incomum para o século XIX, e não chamava as tribos selvagens de "primitivas" e nem as considerava moral ou intelectualmente "inferiores" aos europeus (cf. Smith, 2003b, p. 2). Quanto aos grandes macacos, desde Lamarck, a postulação da origem símia dos seres humanos era patrimônio do pensamento heterodoxo, e Wallace "ficou fascinado com a possibilidade de estudá-los no seu habitat. Para ele, era perfeitamente aceitável que tivéssemos um ancestral comum com os orangotangos" (Ferreira, 1990, p. 47). Graças à sua pequena fama, a Royal Geographical Society pagou sua passagem de ida, e ele alcançou Singapura em 20/04/ 1854, permanecendo na Oceania de 1854 a 1862. Visitou Bornéu, Java, Sumatra, Timor, Molucas, Nova Guiné, Málaca, Aru e dezenas de pequenas ilhas; fez por volta de setenta expedições, cobriu 14,000 milhas e coletou 125660 espécies, sendo mais de mil anteriormente desconhecidas (cf. Smith, 2003a, p. 4; Tort, 1996, p. 4567).

Em fevereiro de 1855 , em Sarawak, irritado com um artigo publicado em 1854 por Edward Forbes, no qual este afirmou que os fósseis mostram que o número de gêneros extintos atinge dois máximos, um nas eras geológicas mais antigas e outro nas recentes, com um mínimo nas eras intermediárias, Wallace redigiu um manuscrito intitulado Sobre a lei que regula a introdução de novas espécies, publicado em Londres em setembro de 1855 (Wallace, 2003a), traduzido e publicado a seguir. A interpretação 


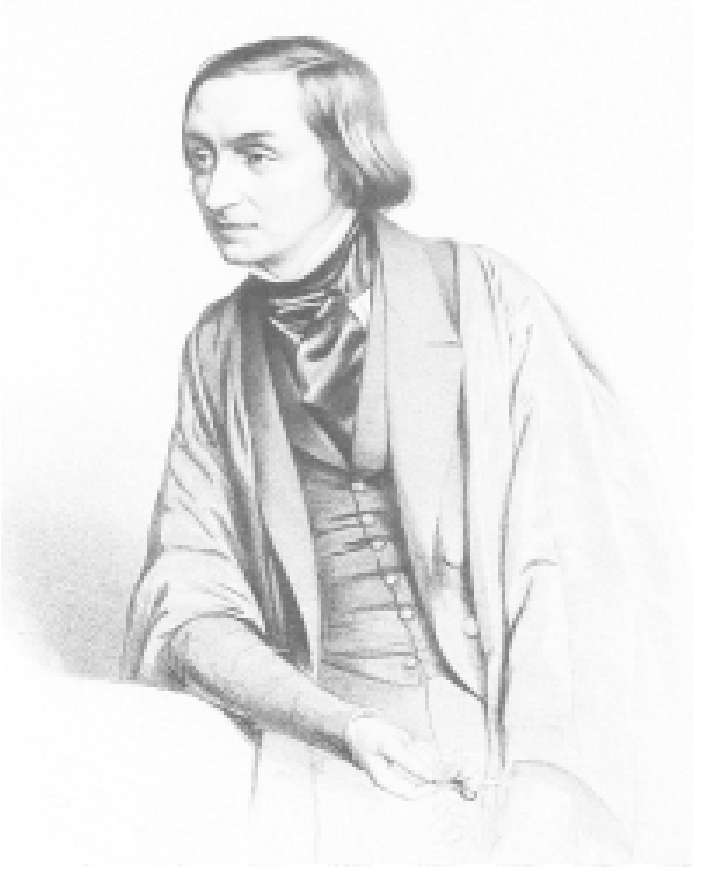

Figura 3. Edward Forbes, ao sustentar a tese da polaridade, levou seu adversário teórico Wallace a publicar o artigo de 1855 . não-progressiva dos registros fósseis de Forbes estava em franca oposição à de Wallace, que teve de agir; em o8/o1/1858, escreveu para Bates:

Foi a publicação da teoria de Forbes que me decidiu a escrever e publicar [o artigo], pois fiquei aborrecido de ver um tal absurdo formulado quando uma hipótese tão simples explica todos os fatos (apud Ferreira, 1990, p. 37).

Maduro intelectualmente e disposto ao confronto teórico, nesse artigo de 1855 , Wallace refina a teoria da descendência de Chambers e apresenta-se francamente como evolucionista. Fornece também uma causa natural para a divergência, ou origem das espécies, sustentando que o mecanismo geológico de separação geográfica das populações de m Buffon, abrange todos os fatos da biouma espécie que descreve, talvez inspirado em Buffon, abrange todos os fatos da biogeografia e permite apresentar o sistema natural estruturado na forma de uma árvore ramificada. Essa disposição marcou o fim da sistemática tal como Lineu a entendeu, pois seu criacionismo o fez conceber e classificar as espécies de modo descontínuo, pressupondo a inexistência de relações parentais reais nas categorias taxonômicas superiores; por conseguinte, Wallace (e também Darwin) substituiu o lineano centro de origem único das espécies pela ancestralidade comum entre elas. Não havia mais espaço para uma concepção tal como Lineu delineou em seu Sistema natural:

os continentes, nas primeiras idades do mundo, jaziam imersos embaixo do mar, exceto uma só ilha em meio ao imenso oceano, na qual todos os animais viviam comodamente e todos os vegetais foram produzidos na maior exuberância ... devemos conceber o Paraíso situado sobre o equador (apud Espinosa \& Bousquets, 1993, p. 29).

De autor que fortemente o influenciou, Lyell tornou-se o principal adversário teórico de Wallace, quanto à sua pretensão de ter solucionado o problema das condições 
para o surgimento de uma nova espécie, tema que o veterano geólogo atacou em seus Principios de geologia. Nessa obra, para criticar Lamarck, Lyell adotou a idéia de A. de Candolle, de que as espécies vegetais ou animais ocupam uma "estação", ou seja, que cada uma delas está adaptada a um conjunto limitado de circunstâncias ambientais; ora, se uma mudança lenta ou seu arremate geológico drástico mudar as condições físicas do habitat, deve haver extinção de espécies. Contudo, firmemente em oposição ao transformismo, Lyell sustentou que, tão logo surgissem, os espaços vazios deixados pela extinção seriam rapidamente ocupados pelas formas vivas já existentes e, conseqüentemente, não haveria tempo para a lenta transformação proposta por Lamarck (cf. Papavero \& Bousquets, 1994, p. 3). Wallace, por sua vez, no artigo de 1855 , observa que barreiras geológicas separam periodicamente a população de uma espécie e que os novos grupos assim formados passam a ter uma história distinta que, com o tempo, conduzi-los-ia à divergência de forma. Cada uma dessas populações apartadas não tem que ocupar uma região tornada vazia por extinções, no fim de um período de modificações geológicas, mas nela se desenvolve, moldando-se paulatinamente para sobreviver às lentas e graduais alterações de seu ambiente físico.

Anova solução impressionou Lyell que, apesar de criacionista, percebeu um novo delineamento para o transformismo; para saber sua opinião, escreveu a Darwin, cuja inclinação evolucionista era conhecida dos amigos mais próximos desde sua carta de 11/o1/1844 para Hooker, na qual disse estar:

quase convencido (diversamente da opinião que possuía ao começar) de que as espécies não são (é como confessar um assassinato) imutáveis. Que os céus me livrem dos disparates de Lamarck, tais como uma 'tendência à progressão', 'adaptações pela lenta vontade dos animais' etc. Mas as conclusões a que sou levado não são muito diferentes das dele - embora os meios de mudança sejam totalmente. Penso que descobri (que presunção!) o modo simples pelo qual as espécies se tornam primorosamente adaptadas aos vários fins (Correspondence, III, p. 2).

Em outra carta, menos conhecida, endereçada para Leonard Jenyns em 12/10/ 1844, Darwin também admitiu seu evolucionismo:

Continuo regularmente lendo e coletando fatos sobre a variação de animais e plantas domésticos e sobre a questão do que são as espécies; possuo um grande corpo de fatos e penso que [deles] posso extrair algumas sólidas conclusões. A conclusão geral a que tenho sido lentamente conduzido, a partir de uma convicção diretamente oposta, é que as espécies são mutáveis e que as espécies aparentadas são 
co-descendentes de um estoque comum. Sei o quanto me exponho à reprovação por uma tal conclusão, mas ao menos tenho honesta e vagarosamente chegado a ela (Correspondence, III, p. 67-8).

Justificando-se por não adotar a posição de Wallace, em abril de 1856, Darwin apresentou sua teoria evolucionista por seleção natural para Lyell, num encontro familiar (cf. Horta, 2003, p. 218, n.1); tempos depois, anexo à carta de 5/og/1857, remeteu um resumo de sua teoria para o naturalista norte-americano Asa Gray (Correspondence, VI, p. 445).

Muito antes de Wallace, Darwin concebeu sua teoria evolucionista por seleção natural no outono de 1838, segundo seu Diário D (cf. Correspondence, III, p. 3); em 1842, escreveu o texto hoje conhecido como Esboço de 1842 (Darwin, 1996, p. 17-69), um resumo de sua teoria que em 1844 ampliou; em 5/o7/1844, remeteu uma carta para sua esposa Emma Darwin, confiando-lhe o manuscrito:

Acabei de terminar o meu esboço da minha teoria das espécies. Se, como creio, ela for verdadeira \& se ela for aceita mesmo por [apenas] um juiz competente, será um considerável passo na ciência. Portanto, escrevo esta, no caso de minha súbita morte, como meu mais solene e último pedido ... a sua publicação (Correspondence, III, p. 4,3).

Anos mais tarde, Joseph Hooker, na carta de 3o/o6/18 8 para a Sociedade Lineana de Londres, afirmou ter lido o esboço ainda em 1844 (cf. Papavero \& Bousquets, 1994, p. 106); contudo, a correspondência de Darwin evidencia que esta afirmação do botânico inglês deve-se a um lapso de memória, e que ele leu a cópia de Darwin, nela fez anotações e, em seguida, remeteu notas críticas para Darwin no início de 1847 (cf. Correspondence, IV, p. 21; Correspondence, VII, p. 118, n. 3). Por fim, na comunicação conjunta de Darwin e Wallace de $1 / 7^{/ 18} 5^{8}$, lida na Sociedade Lineana, o núcleo da teoria de Darwin foi apresentado à comunidade científica (cf. Papavero \& Bousquets, 1994, p. 107-9).

Acerca da aguardada apreciação de Darwin quanto ao artigo de 1855 de Wallace, aquele escreveu em seu exemplar: "Artigo de Wallace: lei da distribuição geográfica; nada verdadeiramente novo"; em duas outras passagens, apontou que, para Wallace, “tudo parece criação!" (apud Tort, 1996, p. 4568). Com efeito, Wallace serviu-se da palavra "criação" por quinze vezes ao longo do artigo, enquanto em nenhuma oportunidade falou sobre transmutação ou transformação (mas somente em "sucessão cronológica ou geológica dos seres organizados", ou ainda, em "criação sucessiva") (cf. Tort, 1996, p. 4568). Quanto à segunda objeção, é relevante salientar que o próprio 
Darwin, no Esboço de 1842 empregou a palavra "criação" com a mesma freqüência que Wallace o fez no artigo de 1855 e com o mesmo deslizamento conceitual (para ambos, "criação" passou a significar continuidade natural, em oposição ao criacionismo, no qual há descontinuidade miracular); na recapitulação e conclusão de $A$ origem das espécies, valeu-se de uma retórica criacionista para se antecipar às críticas que julgava muito prováveis (cf. Darwin, 1978, p. 243) Talvez, nesse ponto, tenha faltado sensibilidade para Darwin perceber que Wallace trilhava exatamente o seu caminho.

Desde que Darwin assim apreciou o artigo de 1855, a tradição darwinista fixou o entendimento de que nesse texto "Wallace não descobriu um mecanismo de produção de espécies novas" (Tort, 1996, p. 4568). Embora a lei de Sarawak (cf. notas 1 e 11) sintetize corretamente os dados biogeográficos e paleontológicos dispersos e inexplicados, tal como a descendência natural na sucessão das espécies e na sistemática, o artigo "revela um vazio de ignorância do modus operandi da 'transição de uma espécie a outra" (Tort, 1996, p. 4568). A seqüência dessa avaliação costuma manter que apenas no artigo de $185^{8}$, intitulado "Sobre a tendência das variedades a afastarem-se indefinidamente do tipo original” (Wallace, 2003b), Wallace apresentou um mecanismo para a evolução, similar à seleção natural e que reúne as noções de variação, luta pela vida e sobrevivência diferencial das variedades favorecidas. Assim, sempre ocupados em avaliar a importância do pensamento de Wallace relativamente a Darwin, os darwinistas costumam manter que, "no total, o artigo de 1855 não exerceu senão uma influência indireta sobre o trabalho de Darwin" (Tort, 1996, p. 4568).

Com efeito, a observação feita por Darwin sobre a inexistência de uma novidade absoluta no artigo de 1855 de Wallace procede, no sentido de que o primeiro já trilhara esse caminho: em julho de 1837, Darwin escreveu em seu caderno que, "se deixarmos as conjecturas às soltas, podemos dizer que os animais devem compartilhar da nossa origem através de um ancestral comum" (apud Ferreira, 1990, p. 21). Porém, para o resto do mundo, a reunião e o desenvolvimento das teses de Buffon, Chambers, Strickland e outros, num todo atualizado, articulado e refinado, constituía novidade! E é surpreendente que Darwin não tenha percebido isso.

Afora o motivo descoberto pelos historiadores, em virtude do qual Darwin não apreciou tanto quanto Lyell o artigo de 1855 , a saber, o aparente criacionismo de Wallace, efetivamente o primeiro não poderia ter reconhecido no texto do jovem naturalista uma extraordinária relevância, pois a continuidade de todo o vivo (em oposição à descontinuidade criacionista) e a representação arborescente do sistema de classificação natural constavam no Esboço de 1842, de Darwin. O experimentado naturalista também sabia que a extinção, ao eliminar as formas intermediárias, faz surgir lacunas entre as espécies, os gêneros e as famílias atuais. Por fim, quanto ao processo motor proposto para a evolução (a separação e o isolamento geográficos da população de uma espécie 
por eventos geológicos), de há muito, Darwin se convencera da centralidade do conceito de seleção natural e trabalhava lentamente para evidenciá-lo numa obra extensa; assim, ele pôde perceber facilmente que Wallace expunha sua solução para a origem das espécies em termos de princípios de geologia - um continuador de Lyell, e não uma ameaça à sua prioridade.

Com efeito, nessa primeira fase de seu pensamento, Wallace acreditava poder resolver todos os fatos relativos à evolução através de sua hipótese da especiação por separação geográfica, estando tão certo disso que não pôde perceber que as inúmeras espécies existentes na parte contínua de territórios continentais não se encaixavam na proposta; no artigo de 1855, embora haja descendência e divergência na história dos seres vivos, não há ainda em Wallace os temas da luta pela existência e, principalmente, da seleção natural, conceitos que oferecem uma satisfatória autonomia para a biologia. Contudo, apenas três anos depois, o pensamento de Wallace sofreria uma profunda inflexão, e ele haveria de surpreender Darwin com um novo artigo (cf. Horta, 2003b).

Todavia, a notável obra de Wallace merece ser lida por si só, e não pelo efeito que produziu em Darwin ou em virtude de sua futura aproximação com o pensamento do autor de $A$ origem das espécies. Se assim fizermos, estaremos em condições de perceber que Wallace, em 1855 , em sua perspectiva e em face ao estado do conhecimento da época, já possuía uma teoria evolucionista completa, com um mecanismo causal; que ele, em 1858, abandonou o mecanismo da separação geográfica como causa da evolução (é impressionante, mas o texto de $185^{8}$ sequer o cita) em favor da seleção natural das variedades; e que parece justificado falar da primeira e da segunda teoria evolucionista de Wallace. Por fim, é importante observar que, para os evolucionistas atuais, a hipótese inicial de Wallace, aprimorada, tem grande relevância; pois, como aponta Bernard Michaux, a biologia cladística "considera o espaço como um elemento ativo no processo evolucionário" (Michaux, 2003, p. 11).

\section{Marcio Rodrigues Horta}

Membro do Projeto Temático

"Estudos de filosofia e história da ciência" da FAPESP, doutorando do Departamento de Filosofia da Universidade de São Paulo. marciorh@bol.com.br 


\section{REFERÊNCIAS BIBLIOGRÁFIGAS}

\section{Primárias}

DARWIN, C. The origin of species by means of natural selection. Chicago, University of Chicago Press, 1978. . Correspondence. 10 vols. Ed. de F. Burkhardt \& S. Smith. Cambridge, Cambridge University Press, 1985-1997. (Correspondence)

. Esboço de 1842. Rio de Janeiro, Clássicos Econômicos Newton, 1996.

WALLACE, A. "On the law which has regulated the introduction of new species". URL: http:// www.wku.edu/ smithch/wallace/BIOG.htm, artigo de 1855, p. 1-9, obtido em 17/o3/2003a.

. "Sobre a tendência das variedades a afastarem-se indefinidamente do tipo original". Scientiae Studia, 1, 2, 2003b, p. 231-40.

\section{Secundárias}

FERREIRA, R. Bates, Darwin, Wallace e a teoria da evolução. Brasília/São Paulo, Editora da UnB/EDUSP, 1990.

HORTA, M. Um estudo do evolucionismo de Darwin à luz das idéias de Kuhn em filosofia da ciência. Dissertação de mestrado. Departamento de Filosofia, Pontifícia Universidade Católica de São Paulo, 1998.

"O impacto do manuscrito de Wallace de 1858". Scientiae Studia, 1, 2, 2003, p. 216-29.

KUHN, T. A estrutura das revoluções científicas. São Paulo, Perspectiva, 1987 .

MICHAUX, B. "Comment". In: WALLACE, A. "On the law which has regulated the introduction of new species”. URL: http://www.wku.edu/ smithch/wallace/BIOG.htm,obtido em 17/o3/2003.

ESPINOSA, D. \& BOUSQUETS, J. Fundamentos de biogeografías filogenéticas. México, Universidad Nacional Autónoma de México, 1993.

PAPAVERO, N. \& BOUSQUETS, J. Principia taxonômica. Vol. V. México, Universidad Nacional Autónoma de México, 1994.

PAPAVERO, N.; BOUSQUETS, J. \& ABE, J. Fundamentos de biología comparada. Vol. I. México, Universidad Nacional Autónoma de México, 1997.

PAPAVERO, N.; MARICONDA, P. \& RAMOS, M. "A primeira proposta de um supercontinente primitivo no opúsculo de 1764, do barão von Hüpsch-Lonzen”. Scientiae Studia, 1, 3, 2003, p. 337-53.

SMITH, G. Alfred Russel Wallace: A capsule biography. URL: http://www.wku.edu/ smithch/wallace/ BIOG.htm, obtido em $05 / 06 / 2003$ a.

Cronology of the main events in Wallace's life. URL: http://www.wku.edu/ smithch/wallace/ chronol.htm, obtido em $05 / 06 / 2003 \mathrm{~b}$.

TORT, P. Dictionnaire du darwinisme et de l'évolution. Paris, PUF, 1996. 